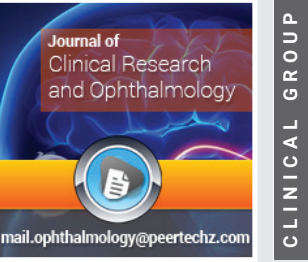

\title{
What ophthalmologists need to know about pandemic of Corona Virus 19
}

\section{Elshimaa Mossa and Alahmady Hammad Alsmman*}

The Department of Ophthalmology, Sohag Faculty of medicine, Sohag University, Sohag, Egypt

Received: 23 June, 2020

Accepted: 30 June, 2020

Published: 01 July, 2020

*Corresponding author: Alahmady Hamad Alsmman, The Department of Ophthalmology, Sohag Faculty of Medicine, Sohag, University, 82524 Sohag, Egypt, Tel: 00201111102698; E-mail: alahmady20@yahoo.com

ORCID: https://orcid.org/0000-0001-6436-5576

Keywords: Covid19; Ophthalmologists; Pandemic

https://www.peertechz.com

Check for updates

\section{Abstract}

Introduction: Severe acute respiratory syndrome coronavirus 2 (SARS-CoV-2) or novel coronavirus 2019 (Covid19) is an emerging life-threatening catastrophe worldwide with no country immune from this problem. Ophthalmologists are in the first line facing this pandemic due to their intimate contact during clinical examination and surgery.

Objective: Ophthalmologists should have base line of knowledge about Covid 19 and sources of infection and methods of transmission. Ophthalmologists have two lines in their practical life outpatient clinic line and surgical line. In this article we tried to help ophthalmologists all over the world to know basics about Covid 19 pandemic and how to deal to decrease risk of infection either in examination in out patient clinic and in operative rooms.

Conclusion: Strong instruction should seriously be followed by ophthalmologists, nurses and workers in outpatient clinics and surgical centers to avoid infection, distance separation and avoiding unneeded exposure should respected.

Lastly all health care should be available for any ophthalmologist or working in this field like regular nasopharyngeal flabs, isolation hospital or even intensive care units when needed as they are in first line facing this dangerous disease.

\section{Introduction}

Since December 2019 the world started a new common misery which is believed to be epidemiologically related to a certain types of Chinese seafood and also wet animal mainly in food market in Wuhan, Hubei Province, China $[1,2]$. Severe acute respiratory syndrome coronavirus-2 (SARS-CoV2) causes a highly contagious disease which is suspected to be a pandemic [3]. On February 2020, outbreak of Coronavirus is considered with large number of morbidity and mortality starting in China and spread to Europe and America and rapidly all over the world the name New Covid19 was given as it discovered in december2019 Novel (New) to differentiate it from ordinary acute respiratory syndrome. Coronavirus (COVID-19, named by WHO and declared COVID-19 a Public Health Emergency of International Concern (PHEIC) and thus a pandemic [4].

Ophthalmologists are especially involved and have a great role in this pandemic. Being in close contact to their patients during examination make them at high risk of getting the infection. In addition to the newly identified ocular manifestations which should be well known to help diagnosing as COVID manifestation and save the patient's life.

In this article epidemiological, microbiological knowledge with understanding pathogenesis and being familiar with clinical picture is our goal, high lighting the newly identified ocular symptoms and signs. Moreover in this pandemic, protective measures are taken to limit spread to decrease both morbidity and mortality, maintain the emergency work which need urgent interventions, and protect ophthalmologists and other Health Care Workers (HCW) in ophthalmology field are also discussed to help them in their facing of this catastrophe.

\section{Microbiology}

According to genetic clustering, there are four types identified of coronaviruses: alpha, beta-, gamma- and delta. The alpha and beta types are the two responsible for diseases in human, as the common respiratory viruses. The SARS-CoV2 and SARS-CoV1 both belong to beta-CoV subtype [5]. The characteristic crown appearance of coronaviruses shown by 
electron micrographs on transmission is the cause for which they so named [3].

COVID-19 is a single, positive-stranded RNA virus with an envelope composed of lipid bilayer [6]. The virus attacks and fuses with the targeted membrane of the host cell. Then it releases RNA into the cytoplasm of the host and translates the proteins of the virus reassembling into new viruses, which exit the cell [7].

\section{Pathogenesis}

COVID-19 patients have respiratory symptoms with higher plasma level of pro-inflammatory cytokines. Patients' sputum show positive real-time Polymerase Chain Reaction (PCR) that confirm infection by COVID-19 [8]. The laboratory studies showed leucopenia with leukocyte counts of $2.91 \times 10 \wedge 9$ cells/L of which $70.0 \%$ were neutrophils. Blood C-reactive protein values above the normal range of $16.16 \mathrm{mg} / \mathrm{L}$. High erythrocyte sedimentation rate and $\mathrm{D}$-dimer also found [8]. The main pathogenesis of COVID-19 infection as a respiratory system targeting virus is severe pneumonia, RNAaemia, with evidence of ground-glass opacities with acute cardiac insult [9]. Marked high blood levels of cytokines and chemokines COVID-19 patients, included IL1- $\beta$, IL1RA, IL7, IL8, IL9, IL10, basic FGF2, GCSF, GMCSF, IFN $\gamma$, IP10, MCP1, MIP1 $\alpha$, MIP1 $\beta$, PDGFB, TNF $\alpha$, and VEGFA. Severely affected cases with severe respiratory destress who admitted to the ICU showed high levels of proinflammatory cytokines including IL2, IL7, IL10, GCSF, IP10, $\mathrm{MCP} 1, \mathrm{MIP} 1 \alpha$, and TNF $\alpha$ [9].

\section{Transmission}

Disease occurs via exposure to heavy droplets that are sneezed or coughed by infected symptomatic patients or even asymptomatic carriers that present in area of 1 to $2 \mathrm{~m}$. Inhalation of theses heavy droplets or touching contaminated surfaces and then touch your mouth, nose, or eye can help transmitting the infection [10]. The virus can survive on surfaces for days and can fortunately be easily destroyed by using disinfectants as hydrogen peroxide or ethanol alcohol $70 \%$ [11]. We should always clearly keep in mind and do not forget that asymptomatic carriers are potential unknown source of COVID-19 infection in addition to convalescent patient who discovered to have prolonged shedding of COVID-19. Yet, to detecte COVID-19 qRT-PCR in those patients remains to be proved by means of viral culture [10].

\section{Clinical picture}

Not all patients are feverish at presentation, but only $43.8 \%$ of patients. $87.9 \%$ develop fever following hospitalization. Only $15.7 \%$ of cases develop severe pneumonia. $23.9 \%$ show no radiologic abnormality on presentation. Diarrhea was reported but it is uncommon. The median incubation period of the virus is 3.0 to 5.2 days [12]. The median hospitalization is 10 days and recovery could be started 2-3 weeks after the symptoms' onset [13].

\section{Ophthalmic manifestations}

Ocular manifestations, including conjunctival hyperemia, chemosis, epiphora, and increased secretions, may be found in mild cases up to sever pneumonia cases. Studies claimed that severe forms of ocular manifestations (e.g. retinitis, anterior uveitis and optic neuritis) are reported in animal models and not in human beings $[14,15]$. The above-mentioned ocular manifestations were reported in patients days before appearance of general manifestations and even can be unilaterally presented [16].

It became well known that Covid-19 infection is accused for causing vascular, venous, and arterial thrombotic complications especially in those patients who have hypercoagulable status. Those patients should be listed among those of high risky patients like elderly, diabetics, immunocompromised patients [17]. Acute ophthalmic artery must be suspected in patients with hypercoagulable states, especially those who complain sudden, painless, and severe visual loss. The optimum regimen of treatment and the significance of $\mathrm{D}$-Dimer for anticoagulation monitoring in Covid-19 remain unclear. Using direct oral anticoagulants or low-molecular-weight-heparin must be considered appropriate at discharge for patients with thromboembolism [18].

Chloroquine (CO) and hydroxychloroquine (HCO) are well known antiviral agents effective against severe acute respiratory syndrome (SARS) virus infection [19]. Treating coronavirus 2019 infection protocols, including both of those agents [20]. Course of $\mathrm{CQ} 500 \mathrm{mg}$ twice daily, for 10 days, or $400 \mathrm{mg}$ of HCQ 4 times daily. These high doses used for treatment of (COVID-19) have raised concerns about retinal affection. Ophthalmologists should be informed with the taken dose, weight of the patient, and duration of use as the primary determinants of risk of retinopathy [21].

OCT macula was done to twelve COVID-19 infected patients in a recent study to detect any effect of OCVID-19 on the retina. All patients showed asymptomatic hyper-reflective lesions at the level of ganglion cell and inner plexiform layers affecting the papillo-macular bundle in both eyes. OCT-angiography and ganglion cells complex analysis did not show any abnormality. Four patients in that study presented subtle cotton wool spots and micro-hemorrhages along the retinal arcade, observed on fundus examination, color fundus photography, and red-free imaging. Visual acuity and pupillary reflexes were normal in all eyes. No symptoms or signs of intraocular inflammation were founds in the patients included in that study [22].

Up till now, there is no evidence suggests that asymptomatic contact lens wearers should stop wearing them to avoid the risk of developing COVID-19. Those wearing spectacles are not protected against SARS-CoV-2. No evidence that that any one form of contact lens material is more likely to increase or reduce the risk of future COVID-19 infection. However, information about this novel coronavirus is still evolving and ophthalmologists must remain attentive to newly emerging findings [23].

To control the pandemic, complete our duties toward our patients, and protect HCW. Ophthalmologists duties include, outpatient clinics, operative theaters, investigative procedures,

Citation: Mossa E, Alsmman AH (2020) What ophthalmologists need to know about pandemic of Corona Virus 19. J Clin Res Ophthalmol. 7(2): 050-053. 
and outpatients' procedures such as (Argon LASER for PRP, ALT) and (YAG LASER capsulotomy, peripheral iridotomy).

\section{A. Outpatients clinic, outpatient procedures and investi- gative procedures}

1- We should decrease the crowd in the clinics widening of spaces between patients, take all protective tools as follow Limitation of outpatient clinic to urgent symptoms like visual loss, Sudden ocular pain or severe symptoms as lacrimation, redness, photopsia and swellings

2- Prevention of relatives to enter the clinic room when patient is independent of assistant or only one relative if needed.

3- All cold cases should delay as regular check on glasses regular annular examination of diabetic retinopathy, regular check of intraocular pressure etc.

4- Widening the time lag between the follow up visits for post- surgery patients as they are the most important among those seeking medical advice.

5- Patients with previous dates for surgeries should be contacted and informed about postponing non-urgent ones due to this emerging situation.

6- Reduction of patients attending the clinic and increasing the duration of service.

History taking concerning fever in the patient or relatives to avoid contact if possible, a thermal scanner in the clinic to detect those with fever [24].

Protective face mask specially N95 should be used for every HCW and face shield in dealing with suspected or confirmed cases.

Regular use of ethanol alcohol $70 \%$, or water and soup for hand disinfection must be done after each patient.

Surgical gloves should be used specially when touch the patient eye or eversion of lids and should be changed between every patient.

Replace the instruments need close contact with patients like direct ophthalmoscope by another keeping distance like Volk9o.

Telemedicine by video visits or timed telephone calls. It can help greatly in filtering acute problems needing urgent visits, medication reconciliation to improve adherence, reassurance, follow-up of chronic conditions, re-assessment of care plans, re-scheduling the upcoming appointments or procedures, and for advertising telehealth service to patients. Rapid construction of a live ophthalmology telemedicine program is mandatory to save lives through social distancing [25].

Investigative procedures should be concerned only by the urgent cases (B-Scan for traumas, fluorescein angiography, OCT and OCT angiography for those of central retinal artery occlusion, retinal vein occlusion, advanced diabetic retinopathy, retinal tears and other urgent cases who cannot withstand delaying).

Lastly for difficult cases video conference or zoom program can be done between doctors to increase experience of young ophthalmologists and manage difficult cases which need consultation

\section{B. For surgical procedures}

Most of instruction above mentioned in outpatient clinic also respected in surgical centers and the following special items should be respected

1- Restriction of surgery to urgent cases only and this is controlled by specialist judge and can be guided by American academy guide of surgical intervention in Corvid 19 [26].

2- All elective surgeries centers like LISIK, cosmetic contact lens should be closed temporarily.

3- Patients should be separated by times to decrease contact and sterilization should be strict between cases specially sites of contact as shin rest and hand holders.

4- All para medical and workers should wear surgical mask in proper manner and face shield with cases of high risk.

5- Relatives should be decreased to only one with the patient in surgical centers.

6- List time should be prolonged and doctors should be given separate times to decrease contact.

7- All surgical maneuvers even simple like intravitreal injection or minor surgeries which need approximation the patient should wear face mask in proper manner covering mouth and nose.

8- Admission of patients in hospital should be restricted and decrease time stay of patients after surgical maneuvers.

9-9-workers and nurses should be attended online training and webinars about sterilization and improving their skills to decrease chance of spread of infection.

10-Young surgeons should increase their skills by online education and listening to well experienced surgeons in webinars not in direct communication in operative rooms.

11- video conference and zoom program to discuss difficult surgical cases and decision making to young ophthalmologists.

\section{Conclusion}

Covid19 is a life-threatening infectious disease, ophthalmologist and their assistants by their work situations are at high risk 
Strong instruction should seriously be followed by ophthalmologists, nurses and workers in outpatient clinics and surgical centers to avoid infection, distance separation and avoiding unneeded exposure should respected.

Lastly all health care should be available for any ophthalmologist or working in this field like regular nasopharyngeal flabs, isolation hospital or even intensive care units when needed as they are in first line facing this dangerous disease.

The authors have not received grant support or research funding.

\section{References}

1. Bogoch II, Watts A, Thomas-Bachli A, Huber C, Kraemer MU, et al. (2020) Pneumonia of Unknown Etiology in Wuhan, China: Potential for International Spread Via Commercial Air Travel. J Travel Med 27: taaa008. Link: https://bit.ly/2Bp861N

2. Lu H, Stratton CW, Tang YW (2020) Outbreak of Pneumonia of Unknown Etiology in Wuhan China: the Mystery and the Miracle. J Med Virol 92: 401402. Link: https://bit.ly/2NFC8AS

3. Atri D, Siddiqi HK, Lang J, Nauffal V, Morrow DA, et al. (2020) COVID-19 for the Cardiologist: A Current Review of the Virology, Clinical Epidemiology, Cardiac and Other Clinical Manifestations and Potential Therapeutic Strategies. JACC: Basic to Translational Science 5. Link: https://bit.ly/2Ah3kmx

4. Zhao S, Lin Q, Ran J, Musa SS, Yang G, et al. (2020) Preliminary estimation of the basic reproduction number of novel coronavirus (2019-nCoV) in China, from 2019 to 2020: A data-driven analysis in the early phase of the outbreak Int J Infect Dis 92: 214-217. Link: https://bit.ly/2YK4FLY

5. Cui J, Li F, Shi ZL (2019) Origin and evolution of pathogenic coronaviruses. Nature reviews Microbiology 17: 181-192. Link: https://go.nature.com/38eEjoB

6. Wu F, Zhao S, Yu B, Chen YM, Wang W, et al. (2020) A new coronavirus associated with human respiratory disease in China. Nature 579: 265-269. Link: https://go.nature.com/2AgIS5n

7. Qinfen Z, Jinming C, Xiaojun H, Huanying Z, Jicheng $H$, et al. (2004) The life cycle of SARS coronavirus in Vero E6 cells. J Med Virol 73: 332-337. Link: https://bit.ly/2CVaKNm

8. Lei J, Li J, Li X, Qi X (2020) CT imaging of the 2019 novel coronavirus (2019nCoV) pneumonia. Radiology 295: 20. Link: https://bit.ly/3dGKCSV

9. Huang C, Wang Y, Li X, Ren L, Zhao J, et al. (2020) Clinical features of patients infected with 2019 novel coronavirus in Wuhan, China. Lancet 395: 497-506. Link: https://bit.ly/2YKFlpn

10. Rothe C, Schunk M, Sothmann P, Bretzel G, Froeschl G, et al. (2020) Transmission of 2019-nCoV infection from an asymptomatic contact in Germany. N Engl J Med 382: 970-971. Link: https://bit.ly/3gofsSn

11. Kampf G, Todt D, Pfaender S, Steinmann E (2020) Persistence of coronaviruses on inanimate surfaces and its inactivation with biocidal agents. J Hosp Infect 104: 246-251. Link: https://bit.ly/2NJj0ly
12. Guan WJ, Ni ZY, Hu Y, Liang WH, Ou CQ, et al. (2020) Clinical characteristics of 2019 novel coronavirus infection in China. medRxiv. Link: https://bit.ly/2Vwpys

13. Wang D, Hu B, Hu C, Zhu F, Liu X, et al. (2020) Clinical characteristics of 138 hospitalized patients with 2019 novel coronavirus-infected pneumonia in Wuhan, China. JAMA 323: 1061-1069. Link: https://bit.ly/2YKX5Rq

14. Wu P, Duan F, Luo C, Liu Q, Qu X, et al. (2020) Characteristics of ocular findings of patients with coronavirus disease 2019 (COVID-19) in Hubei Province China. JAMA Ophthalmology 138: 575-578. Link: https://bit.ly/2YKG2it

15. Seah I, Agrawal R (2020) Can the coronavirus disease 2019 (COVID-19) affect the eyes? A review of coronaviruses and ocular implications in humans and animals. Ocul Immunol Inflamm 28: 1-5. Link: https://bit.ly/31tfq7d

16. Daruich A, Martin D, Bremond-Gignac D (2020) Ocular manifestation as first sign of Coronavirus Disease 2019 (COVID-19): Interest of telemedicine during the pandemic context. Journal Français d'Ophtalmologie 43: 389-391 Link: https://bit.ly/3eSqrDe

17. Fogarty $\mathrm{H}$, Townsend L, Ni Cheallaigh C, Bergin C, Martin-Loeches I, et al. (2020) COVID-19 Coagulopathy in Caucasian patients. British Journal Haematology 189: 1044-1049. Link: https://bit.ly/2YINXgc

18. Dumitrascu OM, Volod O, Bose S, Wang Y, Biousse V, et al. (2020) Acute ophthalmic artery occlusion in a Covid-19 patient on apixaban. Journal of Stroke and Cerebrovascular Diseases 104982. Link: https://bit.ly/2CVgTcp

19. Devaux CA, Rolain JM, Colson P, Raoult D (2020) New insights on the antiviral effects of chloroquine against coronavirus: what to expect for COVID-19? International Journal of Antimicrobial Agents 55: 105938. Link: https://bit.ly/3idoCTb

20. Gao J, Tian Z, Yang X (2020) Breakthrough: Chloroquine phosphate has shown apparent efficacy in treatment of COVID-19 associated pneumonia in clinica studies. Biosci Trend https://bit.ly/2BWujUP. 14: 72- 73

21. Marmor MF (2020) COVID-19 and Chloroquine/Hydroxychloroquine: Is There Ophthalmological Concern? Am J Ophthalmol. Link: https://bit.ly/31uzXsb

22. Marinho PM, Marcos AAA, Romano AC, Nascimento H, Belfort R (2020) Retinal findings in patients with COVID-19. Lancet 395: 1610. Link: https://bit.ly/2AfAX8g

23. Jones L, Walsh K, Willcox M, Morgan P, Nichols J (2020) The CoVID-19 pandemic: Important considerations for contact lens practitioners. Contact Lens and Anterior Eye 43: 196-203. Link: https://bit.ly/2Vwjr70

24. Emara K, Emara AK, Farhan M, Mahmoud S (2020) What orthopedic surgeons need to know about Covid-19 pandemic. J Orthop 21: 275-277. Link: https://bit.ly/2NJiRyM

25. Saleem SM, Pasquale LR, Sidoti PA, Tsai JC (2020) Virtual Ophthalmology: Telemedicine in a Covid-19 Era. Am J Ophthalmol. Link: https://bit.ly/3dKL2bc

26. Coronavirus Guide for Eye Pateints. American Academy of Ophthalmology AAO. Link: https://bit.ly/2BOuPED

Copyright: (c) 2020 Matin EA, et al. This is an open-access article distributed under the terms of the Creative Commons Attribution License, which permits unrestricted use distribution, and reproduction in any medium, provided the original author and source are credited. 